\title{
Role of the Ipsilateral Motor Cortex in Voluntary Movement
}

\author{
Robert Chen, Leonardo G. Cohen and Mark Hallett
}

\begin{abstract}
The ipsilateral primary motor cortex (M1) plays a role in voluntary movement. In our studies, we used repetitive transcranial magnetic stimulation (rTMS) to study the effects of transient disruption of the ipsilateral Ml on the performance of finger sequences in right-handed normal subjects. Stimulation of the M1 ipsilateral to the movement induced timing errors in both simple and complex sequences performed with either hand, but with complex sequences, the effects were more pronounced with the left-sided stimulation. Recent studies in both animals and humans have confirmed the traditional view that ipsilateral projections from $M 1$ to the upper limb are mainly directed to truncal and proximal muscles, with little evidence for direct connections to distal muscles. The ipsilateral motor pathway appears to be an important mechanism for functional recovery after focal brain injury during infancy, but its role in functional recovery for older children and adults has not yet been clearly demonstrated. There is increasing evidence from studies using different methodologies such as rTMS, functional imaging and movement-related cortical potentials, that $\mathrm{M} 1$ is involved in ipsilateral hand movements, with greater involvement in more complex tasks and the left hemisphere playing a greater role than the right.
\end{abstract}

RÉSUMÉ: Rôle du cortex moteur ipsilatéral dans la motricité volontaire. Le cortex moteur primitif ipsilatéral (M1) joue un rôle dans la motricité volontaire. Dans nos études, nous avons utilisé la stimulation magnétique transcrânienne répétitive (SMTr) pour étudier les effets de perturbations passagères du Ml ipsilatéral sur l'exécution d'une succession de mouvements digitaux chez des sujets normaux droitiers. La stimulation du M1 ipsilatéral au mouvement a induit des erreurs dans l'ordre d'exécution de séquences simples et complexes exécutées avec l'une ou l'autre main. Pour les séquences complexes, les effets étaient plus marqués quand la stimulation était faite à gauche. Des études récentes chez les animaux et chez les humains ont confirmé la vision traditionnelle que les projections ipsilatérales de Ml au membre supérieur sont principalement dirigées vers les muscles du tronc et les muscles proximaux. Il y a peu d'indications qu'il existe des connections directes aux muscles distaux. La voie motrice ipsilatérale semble être un mécanisme important dans la récupération fonctionnelle après une lésion cérébrale focale dans la petite enfance, mais son rôle dans la récupération fonctionnelle chez les enfants plus âgés et chez les adultes n'a pas encore été clairement démontré. Il existe de plus en plus d'observations provenant d'études utilisant des méthodologies différentes telles la SMTr, l'imagerie fonctionnelle et les potentiels corticaux reliés aux mouvements, que le Ml est impliqué dans les mouvements de la main ipsilatérale, cette implication étant d'autant plus grande que les tâches sont plus complexes et l'hémisphère gauche jouant un rôle plus considérable que le droit.

Can. J. Neurol. Sci. 1997; 24: 284-291

The first brain stimulation studies of Fritsch and Hitzig, followed by the detailed studies of Sherrington and Penfield, and the clinical observations of Hughlings Jackson established localization of functions in the motor cortex. More recently, a number of techniques such as the electroencephalogram (EEG), positron emission tomography (PET), functional magnetic resonance imaging (fMRI) and transcranial magnetic stimulation (TMS) have become available to elucidate the role of the motor cortex in intact human subjects. Activation of the sensorimotor cortex (SM1) or primary motor cortex (M1) ipsilateral to finger movements in several functional imaging ${ }^{1-4}$ and movementrelated cortical potentials ${ }^{5-7}$ studies challenged the classical view that the contralateral hemisphere exclusively controls fine finger movements. ${ }^{8}$ While these studies provided information on the brain networks involved in the performance of the task, the functional role of these different areas and whether they are required for task performance remain unclear. There is also considerable interest in the role of ipsilateral motor pathways in mediating recovery from brain injury. ${ }^{9-11}$

Here, we first describe the results of our experiments using repetitive transcranial magnetic stimulation (rTMS) to investigate the effects of transient inactivation of $\mathrm{M} 1$ on the performance of finger sequences of different complexities. This is followed by a review of ipsilateral projections from M1 and the

From the Human Cortical Physiology Unit, Human Motor Control Section, Medical Neurology Branch, National Institute of Neurological Disorders and Stroke, National Institutes of Health, Bethesda, Maryland

RECEIVED JANUARY 7, 1997. ACCEPTED IN FINAL FORM APRIL 10, 1997.

Presented in part as the Francis McNaughton Prize lecture at the 31st Meeting of the Canadian Congress of Neurological Sciences, London, Ontario, June 1996.

Reprint requests to: Robert Chen, Building 10, Room SN226, 10 Center Drive MSC1428, NINDS, NIH, Bethesda, MD 20892-1428 USA 
role of ipsilateral motor pathways in mediating recovery from brain injury. The evidence and possible mechanisms for involvement of the ipsilateral M1 in control of voluntary movements are then discussed. We will restrict our discussion to the role of M1, although it is clear that other areas such as the supplementary motor area (SMA) and the premotor cortex are also important in ipsilateral and bilateral movements.

\section{Transcranial Magnetic Stimulation}

TMS is a noninvasive method to stimulate the brain of human subjects. A large, brief electrical current produced by discharging a bank of capacitors is passed though a wire coil placed over the scalp. This produces a rapidly changing magnetic field which induces electrical currents in the underlying brain. ${ }^{12.13}$ Appropriately timed single pulses of TMS can disrupt cortical functions. For example, stimulation of the occipital cortex can suppress visual perception ${ }^{14}$ and stimulation of the sensory cortex can attenuate detection of somatosensory stimuli. ${ }^{15}$ To disrupt more complex functions, a train of pulses at high frequencies (repetitive transcranial magnetic stimulation, rTMS), may be necessary. rTMS of the speech area can cause speech arrest $^{16}$ and when applied over the frontal cortex, may lead to recall deficits. ${ }^{17}$

\section{Effects of Transient Disruption of the Ipsilateral M1 on the Performance of Finger Sequences}

We studied the effects of transient disruption of M1 by rTMS on the performance of finger sequences. ${ }^{18}$ Ten right-handed subjects were first trained to perform a simple and a complex sequence on an electronic piano with either hand. Both sequences were 8 seconds long and had 16 key presses. The simple sequence (5-4-3-2-5-4-3-2-5-4-3-2-5-4-3-2; 5 = little finger, 4 = ring finger, $3=$ middle finger, $2=$ index finger) was ordered and involved adjacent fingers consecutively while the complex sequence (2-5-4-3-3-5-2-4-5-2-3-4-4-2-5-3) was random. We used a water-cooled 8-shaped coil, each loop of which measures $7 \mathrm{~cm}$ in diameter. Motor threshold was the minimum stimulator output that evoked a visible twitch in the resting contralateral first dorsal interosseous muscle (FDI). rTMS at $15 \mathrm{~Hz}$ for $2.3 \mathrm{sec}$ at $120 \%$ of the motor threshold was used for M1 stimulation ipsilateral to the playing hand. For M1 stimulation contralateral to the playing hand, the sequence could be disturbed at lower intensities and the stimuli were reduced to $110 \%$ of the motor threshold. Ten trains were applied for each experimental condition. The precise timing of the key presses was recorded and the numbers of key press and timing errors were counted. Key press errors were defined as pressing the wrong key, pressing an extra key or omitting a key. Timing errors were defined as the time interval between key presses that were outside 2.5 standard deviations of the corresponding control interval in the same subject. The errors rates were compared with that of the control condition with the stimulating coil on the scalp but directed away from the head. We also performed magnetic stimulation of the forearm contralateral to the performing arm to determine the effects of induced movements of the contralateral arm on sequence performance.

As expected, contralateral Ml stimulation led to a large number of key press and timing errors with either hand (Figure 1). Ipsilateral Ml stimulation did not induce a significant increase in key press errors, but caused a significant increase in timing

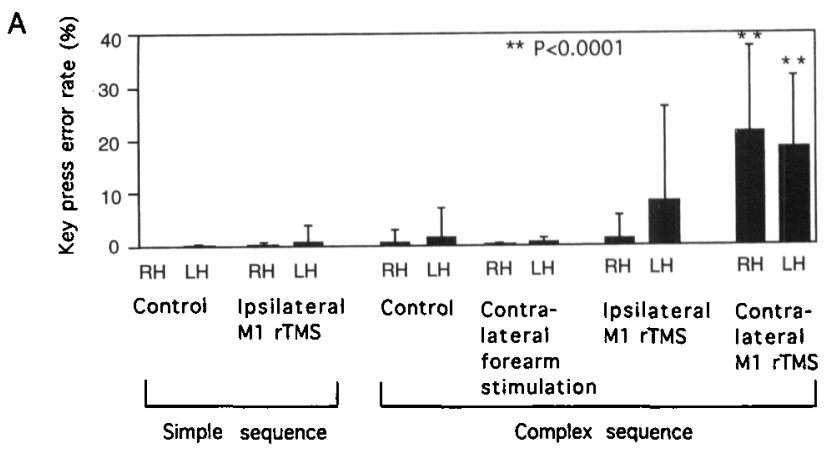

B

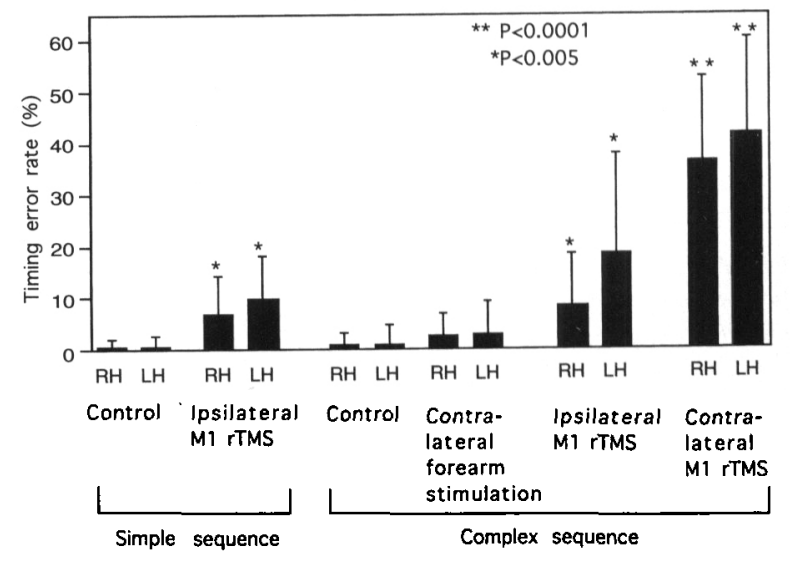

Figure 1: Key press and timing errors in the different experimental conditions. Each error bar represents one standard deviation. Experimental values were compared with control values for the same hand by ANOVA with repeated measures. (A) The key press error rate was significantly increased with contralateral MI stimulation. The increase in error rate for left-sided ipsilateral M1 stimulation did not reach statistical significance. (B) The timing error rate was significantly increased with both ipsilateral and contralateral $r T M S$, but not with contralateral forearm magnetic stimulation. There was also a significant difference between the right and left sides with ipsilateral $M I$ stimulation in the complex sequence $(p=0.019)$. LH, left hand; $R H$, right hand.

errors in both the simple and complex sequences in either hand, with higher error rates in the complex than the simple sequences (Figure 1). With the complex sequence, the error rate was higher in the left than the right hand $(18.6 \%$ vs. $8.3 \%, p=0.019)$. The occurrence of timing errors within the sequence was also different between the right and left sides. With the complex sequence and ipsilateral $\mathrm{Ml}$ stimulation, timing errors in the right hand occurred mainly during rTMS whereas errors in the left hand occurred both during and after rTMS (Figure 2). Magnetic stimulation of the contralateral forearm did not induce a significant increase in key press or timing errors with the complex sequence (Figure 1).

The magnetic field induced by the figure-of- 8 coil is relatively focal and centered on M1. Adjacent areas such as the SMA or premotor cortex (area 6) might also be stimulated, but it is unlikely that more distant areas such as the prefrontal cortex were affected. Transcallosal inhibition is also unlikely to account for the effects of ipsilateral Ml stimulation. Although M1 stimulation may inhibit activity of the ipsilateral arm, ${ }^{19.20}$ our recent studies showed that it is largely mediated at the spinal 


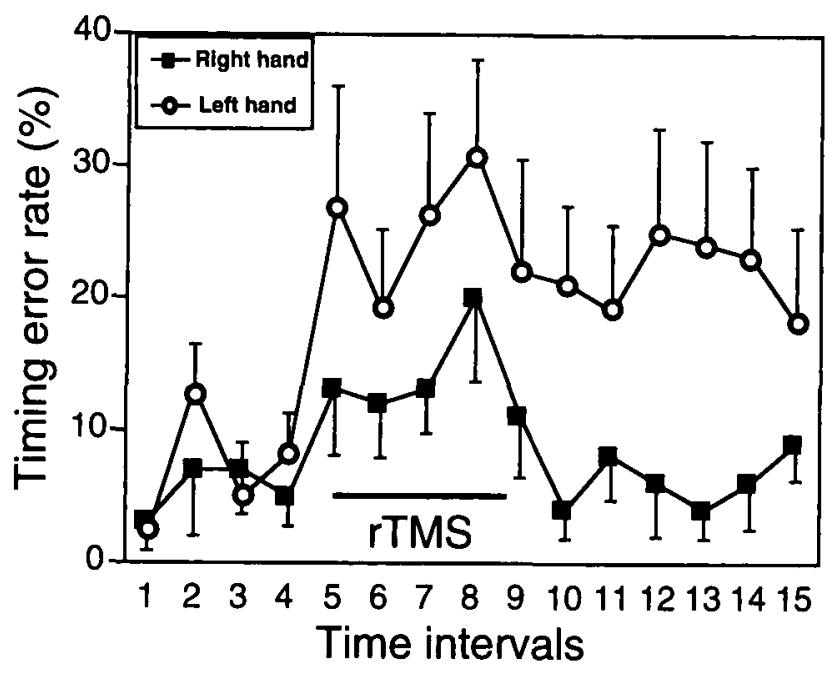

Figure 2: Timing error rate at different time intervals (the time from the beginning of one key press to the beginning of the next key press) for the complex sequence with ipsilateral MI rTMS. Each error bar represents one standard error. For the right hand, mistakes occurred mainly during the stimulation period, and error rates in the pre- and poststimulation periods were similar. In contrast, for the left hand, error rates were significantly higher during both the stimulation period and the poststimulation period compared with the prestimulation period. Modified from Chen et al. ${ }^{18}$

leve ${ }^{21}$ rather than through transcallosal pathways as previously suggested.$^{20}$ In any event, we did not observe a significant reduction of EMG activity in the forearm muscles during performance of the sequence with ipsilateral M1 stimulation. Our findings suggest that the ipsilateral M1 is involved in the control of fine finger movements, with the left hemisphere playing a greater role than the right hemisphere. To put this result in context, we will next review the role of the ipsilateral Ml in control of voluntary movement, and examine the difference between the right and left hemispheres.

\section{Ipsilateral Corticospinal Projections}

M1 projects to ipsilateral muscles via direct and indirect pathways. The direct pathway consists of the uncrossed lateral corticospinal tract, which comprises about $10-15 \%$ of the pyramidal tract fibers ${ }^{22}$ but varies in size considerably from subjectto-subject. ${ }^{23}$ It originates from the trunk and the proximal upper limb area of the motor cortex, and projects mainly to the medial groups of motoneurons in the ventral horn innervating truncal and proximal upper limb muscles. ${ }^{8}$ Indirect connections from M1 project to the medial bulbar reticular formation, which then projects to axial and proximal limb muscles through the ventromedial part of the spinal cord. ${ }^{8,23}$ It is the traditional view that proximal arm movements have bilateral control, but hand and finger movements are controlled exclusively by the contralateral hemisphere. ${ }^{8}$ This is consistent with the finding that each hemisphere of split-brain monkeys controlled contralateral arm, finger and hand movements, but controlled only ipsilateral proximal arm movements. ${ }^{8}$

In humans, TMS has been used to examine ipsilateral pathways from the motor cortex to proximal and distal upper limb muscles. Ipsilateral motor-evoked potentials (MEPs) can be obtained regularly from proximal muscles and sometimes from intrinsic hand muscles. ${ }^{24}$ However, the amplitude of ipsilateral MEPs are much smaller than contralateral MEPs, and high intensities of stimulation are required to elicit them. Ipsilateral MEPs from distal hand muscles are more difficult to elicit than ipsilateral MEPs from proximal muscles, and background muscle activation with averaging of responses from a series of stimuli is usually necessary. ${ }^{19.24}$ Silent periods, which refer to the interruption of voluntary activity and are a measure of the inhibitory effects of TMS, ${ }^{25}$ can also be obtained from both proximal and distal upper limb muscles. ${ }^{19.24}$ The latencies of ipsilateral MEPs and silent periods are longer than that of the contralateral side, suggesting that the ipsilateral effects may be mediated by indirect corticoreticulospinal fibers rather than pyramidal tract fibers. ${ }^{19}$ In truncal and facial muscles, such as the diaphragm, rectus abdominis and masseter, TMS often elicits bilateral responses. ${ }^{26}$ Cross-correlation analysis of surface EMG investigates whether the firing of motor units in different muscles are time-locked to each other, which would suggest a common drive. Homologous truncal muscles were found to be highly correlated, likely due to bilateral corticospinal tract projections. ${ }^{26}$ There was no evidence for a common drive in homologous limb muscles, consistent with the absence of direct ipsilateral corticospinal projections. ${ }^{26}$

In stroke patients, quantitative measurements of muscle strength demonstrated weakness in ipsilateral muscles, particularly in shoulder adduction and wrist extension, but hand strength was comparable to normal subjects. ${ }^{27}$ This is consistent with the projection of the M1 to ipsilateral proximal muscles.

The results of these human studies suggest that ipsilateral projections from $\mathrm{Ml}$ to the upper limb muscles exist but are considerably weaker than contralateral projections. The proximal muscles are mainly targetted, with distal muscles receiving only weak and indirect ipsilateral projections.

\section{Are Ipsilateral Pathways Involved in Recovery from Focal Brain Injury?}

Several authors have raised the possibility that ipsilateral motor pathways play a role in functional recovery from stroke. ${ }^{9.11 .28}$ Fisher $^{28}$ described two patients with good recovery from a previous stroke, but hemiplegia reappeared in the recovered side after another pure motor stroke in the opposite hemisphere. Lee and van Donkelaar" also reported a similar case. A transcranial Doppler study in patients with cortical ischemic stroke showed a greater increase in the flow velocity of the ipsilateral middle cerebral artery during movements of the recovered hand compared to the unaffected hand or normal controls, suggesting that the undamaged hemisphere may play a role in functional recovery. ${ }^{29}$ Reorganization after stroke was studied with PET by examining the changes in regional cerebral blood flow (rCBF) associated with finger movements of both the recovered and unaffected sides. As a group, the stroke patients had significantly increased CBF in the ipsilateral SM1 with movement of the recovered hand but not with movement of the unaffected hand. ${ }^{30,31}$ However, a subsequent report from the same group analyzed individual patients and found ipsilateral SM1 activation in only 4 of 8 patients, and these patients had mirror movements in the unaffected hand when they moved the recovered hand ${ }^{32}$ It was unclear whether activation of the ipsilateral SM1 was related to recovery of function or simply secondary to mirror movements. 
The pattern of central motor reorganization has been studied in hemispherectomy patients ${ }^{33-35}$ and in children with hemiplegic cerebral palsy. ${ }^{36}$ In patients with early hemispherectomy, TMS of the healthy hemisphere produced ipsilateral MEPs at latencies similar to contralateral MEPs, with higher amplitudes in proximal than distal muscles. ${ }^{33.35}$ The ipsilateral representations were topographically different from the contralateral representations. Both $\mathrm{PET}^{34}$ and $\mathrm{TMS}^{34.35}$ studies showed that the ipsilateral representations occupied more anterior and lateral locations than contralateral representations in the healthy hemisphere (Figure 3). Patients with late hemispherectomy had ipsilateral MEPs of longer latencies and lower amplitudes, and had a worse outcome than the early hemispherectomy patients. ${ }^{33.35}$ Carr et al ${ }^{36}$ studied children with hemiplegic cerebral palsy. They reported that in patients with congenital hemiplegia, intense mirror movements and relatively good functions of the affected hand, TMS of the unaffected M1 elicited short-latency MEPs from the ipsilateral FDI muscle. These patients were considered to have suffered their brain insult before 29 weeks of gestation. Ipsilateral MEPs with prolonged latencies were found in some patients without mirror movements; these patients had variable degrees of recovery. In patients with good recovery of the affected hand without mirror movements, stimulation of the affected M1 elicited short-latency MEPs from the affected FDI muscle. Patients with no MEP from the affected FDI with stimulation of the affected or the unaffected M1 all had poor hand functions. These findings suggested that ipsilateral motor pathways from the unaffected hemisphere may play a role in recovery from brain injury occurring early in life. Possible mechanisms include development of new ipsilateral corticospinal projections, double-crossing of contralateral corticospinal fibers, and reinforcement of existing ipsilateral corticospinal pathways. Ipsilateral MEPs of prolonged latency may be due enhanced corticoreticulospinal pathways. ${ }^{33}$

TMS has also been used to examine the ipsilateral corticospinal projection in patients who recovered from stroke. Palmer et al. ${ }^{10}$ recorded post-stimulus time histograms of single motor units from the biceps muscle in 9 recovered stroke patients, and found no evidence that the ipsilateral fast corticospinal tract was responsible for the recovery. Turton et al. ${ }^{37}$ reported a longitudinal study of 21 stroke patients. Ipsilateral MEPs in the affected arm were more common and of longer latencies than those in the unaffected arm, and they were observed mainly in the proximal muscles and occasionally in hand muscles. However, since ipsilateral responses were more common among patients who had poor recovery than patients with good recovery, it is unclear whether they play any role in functional recovery from stroke. In contrast, Caramia et al. ${ }^{38}$ reported ipsilateral MEPs in hand muscles in 13 patients who had rapid recovery from hemispheric stroke. The ipsilateral MEPs were elicited only with muscle activation and had higher thresholds, lower amplitudes but, surprisingly, shorter latencies compared to contralateral MEPs. ${ }^{38}$ All these studies used large circular ${ }^{10,38}$ or double-cone ${ }^{37}$ magnetic coils. Palmer et al.$^{10}$ and Turton et al. ${ }^{37}$ did not test high-intensity stimulations because that may activate the contralateral hemisphere. Since the thresholds for ipsilateral responses are considerably higher than those for contralateral responses, ${ }^{19.24}$ the contribution of ipsilateral MEPs may have been underestimated. On the other hand, Caramia et al ${ }^{38}$ may have activated the contralateral hemisphere with high-stimulus intensities. Therefore, the role of ipsilateral motor pathways in recovery from stroke remains unclear.

\section{Evidence for Involvement of the Ipsilateral M1 in Hand Movements}

Recordings from neurons ('task-related' neurons) in Ml of monkeys that are consistently activated in relationship to task performance, provided physiological evidence for ipsilateral control of voluntary movements. In a study of simple movement involving digit and hand muscles in monkeys, most of the taskrelated neurons identified in the $\mathrm{Ml}$ were related to contralateral movements; $8 \%$ were related to ipsilateral movements. ${ }^{39}$ In the SMA and the premotor cortex, about one-half of the neurons exhibited premovement activity changes before both ipsilateral
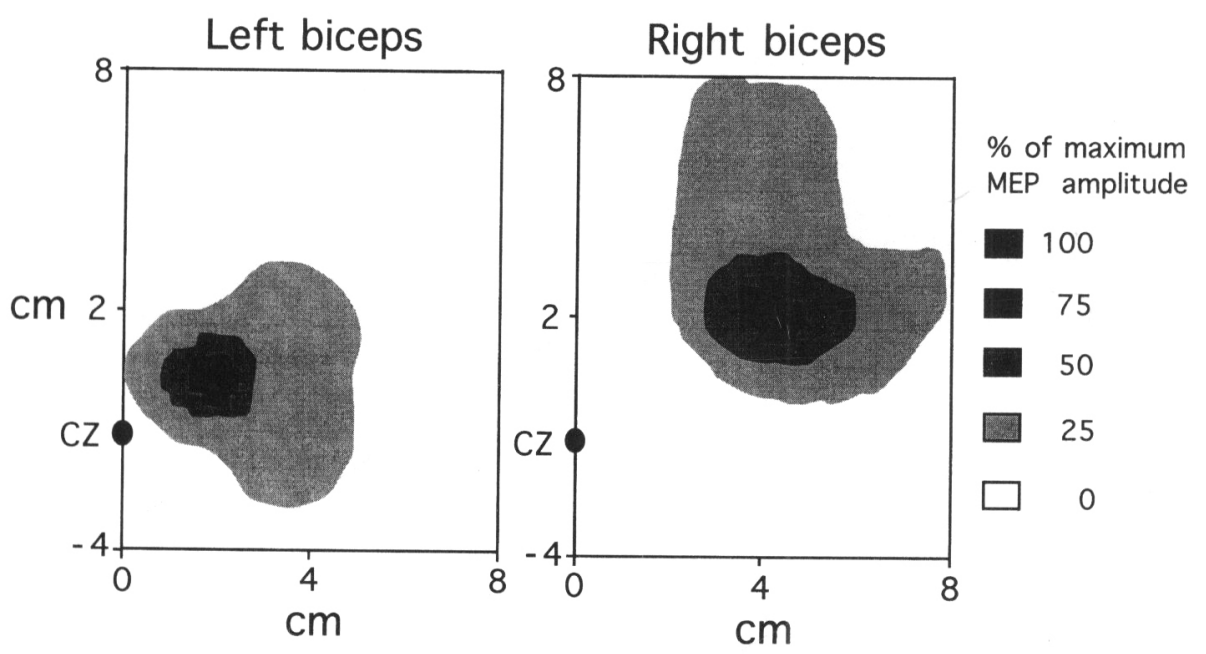

Figure 3: Motor representation of the left and right biceps in the right hemisphere of a 32-year-old man with congenital left porencephalic cyst and hemispherectomy at age 7. CZ refers to the position of the vertex in the international 10-20 system. The MEP amplitudes evoked by TMS with a focal figure-of-eight coil from different scalp locations are shown as percentages of the maximum MEP amplitude. The representation of the right (ipsilateral) biceps was anterior and lateral to that of the left biceps. 
and contralateral movements. ${ }^{39}$ There may also be a subregion of the $\mathrm{Ml}$ between the digit and face representations where the majority of cells are related to ipsilateral or bilateral hand movements..$^{40}$ Most of the ipsilateral or bilateral task-related neurons are nonpyramidal tract neurons, illustrating the importance of indirect pathways for ipsilateral arm control. ${ }^{41}$

Several PET, ${ }^{2,4} \mathrm{fMRI}^{1,3,42-44}$ and movement-related cortical potential $^{5}$ studies demonstrated activation of the ipsilateral SM1 or M1 during execution of finger sequences. In contrast, some early PET studies ${ }^{45,46}$ failed to find increased activity of the ipsilateral SM1; another PET study ${ }^{47}$ showed activation of ipsilateral SM1 with shoulder but not with hand movements. These differences likely are related to the sensitivity of the methods used, because ipsilateral $\mathrm{Ml}$ activation is about 20 times weaker than contralateral M1 activation with right hand movements. ${ }^{3}$ The movement performed by the subject is another important factor, since complex tasks may activate the ipsilateral M1 more often than simple tasks (see below). In some normal subjects, mirror movement of the contralateral arm is detectable by EMG monitoring, especially if the active arm is near maximal effort, although there is generally no observable movement. ${ }^{48,49}$ However, the amount of involuntary EMG activity is less than $1 \%$ of the active arm. Therefore, subclinical mirror movement is unlikely to account for ipsilateral activation observed in imaging studies. ${ }^{49.50}$

\section{Difference Between Simple and Complex Sequences}

We found more errors in the complex sequence than the simple sequence with ipsilateral Ml stimulation, suggesting that the ipsilateral Ml may be more important in complex than simple hand movements. Ipsilateral Ml activation was more consistent in fMRI studies that employed a more complex task of opposition of the thumb with each of the remaining four fingers ${ }^{3}$ than a simpler task of tapping only the middle finger. ${ }^{44}$ Two studies comparing simple and complex movements found ipsilateral MI activation only during the complex but not the simple task. ${ }^{1,2}$ In the fMRI study of Rao et al.,' significant activation of the ipsilateral Ml was observed with tapping four fingers in sequence (e.g., 3-5-4-2) but not with the simpler movement of tapping with all fingers (except thumb) in unison. In the PET study of Shibasaki et al., ${ }^{2}$ rCBF was significantly increased in the ipsilateral SM1 during performance of a complex sequence (opposition of fingers 2-2-3-4-4-4-5-5 to thumb and reverse) but not with a simple sequence of sequential opposition of four fingers against the thumb. However, Sadato et al. ${ }^{4}$ demonstrated similar activation of the ipsilateral Ml with four sequences of varying complexities. The differences between the sequences were mainly due to longer sequence length in more complex sequences. Thus, it appeared that the ipsilateral Ml is more involved if the movements are in a sequence rather than single repetitive movements, but not necessarily with longer sequences.

The movement-related cortical potential is another method to examine cortical activation. In these studies, EEG recordings time-locked to the onset of these movements are averaged. A long duration negative shift, known as Bereitschaftspotential (BP) or readiness potential, can be recorded more than $1 \mathrm{sec}$ prior to onset of voluntary movement. The BP is followed by a steeper negative slope (NS') beginning about $500 \mathrm{msec}$ before EMG onset, and by the motor potential (MP) occurring around
$100 \mathrm{msec}$ prior to EMG onset. Subdural EEG recordings showed that these potentials arise from localized areas from the $\mathrm{SMI}^{51}$ and the SMA. ${ }^{52}$ With simple movements of one finger, BP but neither NS' nor MP were recorded in the ipsilateral M1 with subdural recordings, while $\mathrm{BP}$, NS' and MP were seen at the contralateral M1 and SMA bilaterally. ${ }^{553}$ However, performance of a complex sequence (sequential extension of index and middle finger) was associated with higher amplitudes of the NS' over the SMA and SM1 bilaterally than a simple (simultaneous extension of index and middle finger) sequence.?

Event-related desynchronization (ERD), which refers to the decline of EEG power occurring 1.5 to $2 \mathrm{sec}$ before movement onset, is another measure of cortical activation and appears to be due to physiological mechanisms different from movementrelated cortical potentials. ${ }^{54} \mathrm{~A}$ study of ERD in the alpha frequency band $(8-12 \mathrm{~Hz})$ showed unilateral cortical activation with a simple motor task (tapping), but bilateral activation with a complex task (sequential finger opposition). ${ }^{6}$

Although it is generally held that ipsilateral hand functions are not affected by stroke, there are reports of impaired ipsilateral fine finger movements after hemispheric lesions. Brodal, in his self-report, ${ }^{55}$ described difficulty with writing and other fine motor tasks with his right hand following a right hemispheric stroke. Jones et al.$^{56}$ found significant impairment of ipsilateral sensorimotor functions measured with computerized tracking tasks in patients with unilateral cerebral infarctions, although there was only marginal impairment in grip strength. ${ }^{56}$ These findings suggest that brain areas involved in sensorimotor functions have some degree of ipsilateral motor control. However, it is unclear from these reports which areas, such as the ipsilateral M1, SMA, premotor cortex or a combination of these, are important in causing these deficits.

\section{Difference Between Right and Left Hemispheres}

We found significantly more errors with left-sided ipsilateral M1 stimulation than right-sided ipsilateral M1 stimulation during performance of the complex sequence, suggesting a greater degree of ipsilateral involvement in the left M1 than the right M1 in our right-handed subjects. The occurrence of timing errors within the sequence also differed between the two sides. Left-sided ipsilateral M1 stimulation disrupted timing of the complex sequence in the stimulation and post-stimulation periods, while right-sided $\mathrm{M} 1$ stimulation caused timing errors only in the stimulation period. One explanation for these observations is that the left MI is more involved in processing or planning motor sequences. These findings are consistent with fMRI studies that showed substantially more ipsilateral Ml activation with left hand movements than right hand movements, especially in right-handed subjects. ${ }^{42,43}$ In the study of Kim et al., ${ }^{42}$ the number of pixels activated in the right M1 was only 1.3 times more than in the left M1 with right-handed subjects performing left hand sequential finger-to-thumb opposition movement. Similarly, movement-related cortical potentials studies found a greater contralateral preponderance of BP for finger movements of the dominant hand for both right- and left-handed subjects. ${ }^{7}$ Studies of patients with corpus callosotomy and agenesis of the corpus callosum also suggested that the left hemisphere dominates in ipsilateral and contralateral control of many aspects of distal limb movements. ${ }^{57}$

These findings may explain behavioral studies that showed 
more ipsilateral deficits in patients with left hemispheric damage than those with right hemispheric damage. These deficits include finger-tapping speed, ${ }^{58}$ manual sequences, ${ }^{59}$ eye-arm coordination $^{60}$ and the difference exists in patients without apraxia. ${ }^{61}$ Temporal discrimination ${ }^{62}$ and the timing of movement sequences ${ }^{63-65}$ are particularly affected, consistent with the suggestion that the left hemisphere is important in processing rapid, temporal information. ${ }^{62}$

\section{The Role of the Ipsilateral M1}

We have reviewed anatomical and physiological studies which indicated little evidence for direct ipsilateral connection from the M1 to distal hand muscles. On the other hand, functional imaging and physiological studies, including our rTMS study, showed that the ipsilateral Ml is involved in performance of complex finger movements. How can these findings be reconciled? One possibility is that the less direct connections are active. An additional explanation is that the ipsilateral M1 is not directly involved in activating spinal motoneurons required to execute these movements, but is more involved in the planning and the higher-order organization of movements. This is supported by the greater involvement of the ipsilateral M1 in complex compared to simple sequences in rTMS, ${ }^{18}$ functional imaging, ${ }^{1,2}$ and movement-related cortical potential studies. ${ }^{7}$ In addition, the occurrence of the early BP component of movement-related cortical potentials, but not the later NS' or MP components in the ipsilateral $\mathrm{M} 1$, is consistent with the suggestion that the ipsilateral M1 participates in movement preparation, whereas the contralateral cortex generates the discharges necessary to produce the actual movement. ${ }^{5}$

Although the contralateral M1 is traditionally considered to be an executive locus for simple voluntary movements, ${ }^{66}$ there is increasing evidence to suggest that it also operates at a higher hierarchial level. In the monkey, about one-third of the taskrelated neurons in $\mathrm{M} 1$ are active during movement preparation rather than movement execution, ${ }^{67}$ and many of them are related to location of the target but not the direction of limb movement. ${ }^{68} \mathrm{M} 1$ is also involved in cognitive tasks such as mental rotation. ${ }^{69}$ Lesion studies showed that $\mathrm{M} 1$ is important in spatiotemporal organization and in planning muscle activity. ${ }^{70}$ In humans, TMS mapping ${ }^{71,72}$ and $\mathrm{fMRI}^{73}$ studies demonstrated reorganization of the $\mathrm{M} 1$ during motor learning. We also studied the effects of rTMS of the contralateral M1 on the performance of piano sequences. ${ }^{74}$ The stimulus intensity required to disrupt a complex sequence is lower than that required to disrupt a simple sequence, suggesting that the contralateral M1 is not only involved in movement execution, but also in movement preparation and complexity coding. It appears that the role of the contralateral M1 in movement preparation and coding of movement complexity is shared by the ipsilateral M1.

\section{Conclusions}

Involvement of the ipsilateral M1 in finger movements can be demonstrated in studies using TMS, PET, fMRI, and movementrelated cortical potentials. These different studies are complementary to each other, since each method has its advantages and limitations. Although its importance is clearly less than that of the contralateral M1, the ipsilateral M1, especially the left side, appears to play a role in movement planning and organization. This may relate to ipsilateral deficits in patients with hemispheric lesions.

\section{ACKNOWLEDGEMENT}

We thank Devera Schoenberg, M.S., for skillful editing. This work was supported by the NINDS intramural program.

\section{REFERENCES}

1. Rao SM, Binder JR, Bandettini PA, et al. Functional magnetic resonance imaging of complex human movements. Neurology 1993; 43: 2311-2318.

2. Shibasaki H, Sadato N, Lyshkow H, et al. Both primary motor cortex and supplementary motor area play an important role in complex finger movement. Brain 1993; 116: 1387-1398.

3. Kim S-G, Ashe J, Georgopoulos AP, et al. Functional imaging of human motor cortex at high magnetic field. J Neurophysiol 1993; 69: 297-302.

4. Sadato N, Cambell G, Ibáñez V, Deiber M-P, Hallett M. Complexity affects regional cerebral blood flow change during sequential finger movements. J Neurosci 1996; 16: 2693-2700.

5. Neshige R, Lüders $H$, Shibasaki $H$. Recording of movement-related potentials from scalp and cortex in man. Brain 1988; 111: 719736.

6. Pulvermüller F, Lutzenberger W, Preißl H, Birbaumer N. Motor programming in both hemispheres: an EEG study of the human brain. Neurosci Lett 1995; 190: 5-8.

7. Kitamura J-i, Shibasaki H, Takagi A, Nabeshima H, Yamaguchi A Enhanced negative slope of cortical potentials before sequential as compared with simultaneous extensions of two fingers. Electroencephalogr Clin Neurophysiol 1993; 86: 176-182.

8. Brinkman J, Kuypers HGJM. Cerebral control of contralateral and ipsilateral arm, hand and finger movements in the split-brain rhesus monkey. Brain 1973; 96: 653-674.

9. Lemon RN. Stroke recovery. Curr Biol 1993; 3: 463-465.

10. Palmer E, Ashby P, Hajek VE. Ipsilateral fast corticospinal pathways do not account for recovery in stroke. Ann Neurol 1992; 32: $519-525$.

11. Lee RG, van Donkelaar P. Mechanisms underlying functional recovery following stroke. Can J Neurol Sci 1995; 22: 257-263.

12. Barker AT, Jalinous R, Freeston IL. Non-invasive stimulation of the human motor cortex. Lancet 1985; II: 1106-1107.

13. Rothwell JC, Thompson PD, Day BL, Boyd S, Marsden CD. Stimulation of the human motor cortex through the scalp. Exp Physiol 1991; 76: 159-200.

14. Amassian VE, Cracco RQ, Maccabee PJ, et al. Suppression of visual perception by magnetic coil stimulation of human occipital cortex. Electroencephalogr Clin Neurophysiol 1989; 74: 458462.

15. Cohen LG, Bandinelli S, Sato S, Kufta C, Hallett M. Attenuation in detection of somatosensory stimuli by transcranial magnetic stimulation. Electroencephalogr Clin Neurophysiol 1991; 81: 366-376.

16. Pascual-Leone A, Gates JR, Dhuna A. Induction of speech arrest and counting errors with rapid-rate transcranial magnetic stimulation. Neurology 1991; 41: 697-702.

17. Grafman J, Pascual-Leone A, Alway D, et al. Induction of a recall deficit by rapid-rate transcranial magnetic stimulation. NeuroReport 1994; 5: 1157-1160.

18. Chen R, Gerloff $C$, Hallett M, Cohen LG. Involvement of the ipsilateral motor cortex in finger movements of different complexities. Ann Neurol 1997; 41:247-254.

19. Wassermann EM, Fuhr P, Cohen LG, Hallett M. Effects of transcranial magnetic stimulation on ipsilateral muscles. Neurology 1991; 41: 1795-1799.

20. Ferbert A, Priori A, Rothwell JC, et al. Interhemispheric inhibition of the human motor cortex. J Physiol (Lond) 1992; 453: 525546.

21. Gerloff C, Cohen LG, Chen R, et al. Modulatory influence of primary motor cortex on ipsilateral upper extremity. Neurology 1996; 46 (Suppl): A343.

22. Nyberg-Hansen R, Rinvik E. Some comments on the pyramidal tract, with special reference to its individual variations in man. Acta Neurol Scand 1963; 39: 1-30. 
23. Davidoff RA. The pyramidal tract. Neurology 1990; 40: 332-339.

24. Wassermann EM, Pascual-Leone A, Hallett M. Cortical motor representation of the ipsilateral hand and arm. Exp Brain Res 1994; 100: 121-132.

25. Hallett M. Transcranial magnetic stimulation. Negative effects. In Fahn S, Hallett M, Lüders HO, Marsden CD, eds. Negative Motor Phenomena. Advances in Neurology. v. 67. Philadelphia: Lippincott-Raven Publishers, 1995: 107-113.

26. Carr LJ, Harrison LM, Stephens JA. Evidence for bilateral innervation of certain homologous motoneurone pools in man. J Physiol (Lond) 1994; 475: 217-227

27. Colebatch JG, Gandevia SC. The distribution of muscular weakness in upper motor neurone lesions affecting the arm. Brain 1989; 112: 749-763.

28. Fisher CM. Concerning the mechanism of recovery in stroke hemiplegia. Can J Neurol Sci 1992; 19: 57-63.

29. Silvestrini M, Troisi E, Matteis M, Cupini LM, Caltagirone C. Involvement of the healthy hemisphere in recovery from aphasia and motor deficit in patients with cortical ischemic infarction: a transcranial doppler study. Neurology 1995; 45: 1815-1820.

30. Chollet F, DiPiero V, Wise RJS, et al. The functional anatomy of motor recovery after stroke in humans: a study with positron emission tomography. Ann Neurol 1991; 29: 63-71.

31. Weiller C, Chollet F, Friston KJ, Wise RJS, Frackowiak RSJ. Functional reorganization of the brain in recovery from striatocapsular infarction in man. Ann Neurol 1992; 31: 463-472.

32. Weiller C, Ramsay SC, Wise RJS, Friston KJ, Frackowiak RSJ. Individual patterns of functional reorganization in the human cerebral cortex after capsular infarction. Ann Neurol 1993; 33: 181-189.

33. Benecke R, Meyer B-U, Freund H-J. Reorganisation of descending motor pathways in patients after hemispherectomy and severe hemispheric lesions demonstrated by magnetic brain stimulation. Exp Brain Res 1991; 83: 419-426.

34. Cohen LG, Zeffiro T, Bookheimer S, et al. Reorganization in motor pathways following a large congenital hemispheric lesion in man: different motor representation areas for ipsi- and contralateral muscles. J Physiol (Lond) 1991; 438: 33P.

35. Hallett M, Cohen LG, Pascual-Leone A, et al. Plasticity of the human motor cortex. In: Thilmann AF, Burke DJ, Rymer WZ, eds. Spasticity. Mechanism and Management. Berlin: SpringerVerlag, 1993: 67-81.

36. Carr LJ, Harrison LM, Evans AL, Stephens JA. Patterns of central motor organization in hemiplegic cerebral palsy. Brain 1993 116: 1223-1247.

37. Turton A, Wroe S, Trepte N, Fraser C, Lemon RN. Contralateral and ipsilateral EMG responses to transcranial magnetic stimulation during recovery of arm and hand function after stroke. Electroencephalogr Clin Neurophysiol 1996; 101: 316-328.

38. Caramia MD, Iani C, Bernardi G. Cerebral plasticity after stroke as revealed by ipsilateral responses to magnetic stimulation. NeuroReport 1996; 7: 1756-1760.

39. Tanji J, Okano K, Sato KC. Neuronal activity in cortical motor areas related to ipsilateral, contralateral, and bilateral digit movements of the monkey. J Neurophysiol 1988; 60: 325-343.

40. Aizawa $H$, Mushiake $H$, Inase M, Tanji J. An output zone of the monkey primary motor cortex specialized for bilateral hand movement. Exp Brain Res 1990; 82: 219-221.

41. Matsunami K, Hamada I. Characteristics of the ipsilateral movement-related neuron in the motor cortex in the monkey. Brain Res 1981; 204: 29-42.

42. Kim S-G, Ashe J, Hendrich $\mathrm{K}$, et al. Functional magnetic resonance imaging of motor cortex: hemispheric asymmetry and handedness. Science 1993; 261: 615-617

43. Dassonville P, Zhu X-H, Kim S-G, Ugurbil K, Ashe J. Difference in the functional lateralization of cortical motor areas during finger movements. Soc Neurosci Abst 1996; 22: 657.

44. Boecker H, Kleinschmidt A, Requardt M, et al. Functional cooperativity of human cortical motor areas during self-paced simple finger movements. A high-resolution MRI study. Brain 1994; 117: $1231-1239$.
45. Roland PE, Larsen B, Lassen NA, Shinkoj E. Supplementary motor area and other cortical areas in organization of voluntary movements in man. J Neurophysiol 1980; 43: 118-136.

46. Roland PE, Shinhoj E, Lassen NA, Larsen B. Different cortical areas in man in organization of voluntary movements in extrapersonal space. J Neurophysiol 1980; 43: 137-150.

47. Colebatch JG, Deiber M-P, Passingham RE, Friston KJ, Frackowiak RSJ. Regional cerebral blood flow during voluntary arm and hand movements in human subjects. J Neurophysiol 1991; 65: 1392-1401.

48. Hopf HC, Schlegel HJ, Lowitzsch K. Irradiation of voluntary activity to the contralateral side in movements of normal subjects and patients with central motor disturbances. Eur Neurol 1974; 12: 142-147.

49. Forget R, Boghen D, Attig E, Lamarre Y. Electromyographic studies of congenital mirror movements. Neurology 1986; 36: 1316 1322

50. Mayer M, Bötzel K, Paulus W, et al. Movement-related cortical potentials in persistent mirror movements. Electroencephalogr Clin Neurophysiol 1995; 95: 350-358.

51. Neshige R, Lüders H, Friedman L, Shibasaki H. Recording of movement-related potentials from the human cortex. Ann Neurol 1988; 24 : 439-445.

52. Ikeda A, Lüders HO, Burgress RC, Shibasaki H. Movement-related potentials recorded from supplementary motor area and primary motor area. Role of supplementary motor area in voluntary movements. Brain 1992; 115: 1017-1043.

53. Ikeda A, Lüders HO, Shibasaki H, et al. Movement-related potentials associated with bilateral simultaneous and unilateral movements recorded from human supplementary motor area. Electroencephalogr Clin Neurophysiol 1995; 95: 323-334.

54. Toro C, Deuschl G, Thatcher R, et al. Event-related desynchronization and movement-related cortical potentials on the ECoG and EEG. Electroencephalogr Clin Neurophysiol 1994; 93: 380-389.

55. Brodal A. Self-observation and neuro-anatomical considerations after stroke. Brain 1973; 96: 675-694.

56. Jones RD, Donaldson IM, Parkin PJ. Impairment and recovery of ipsilateral sensory-motor function following unilateral cerebral infarction. Brain 1989; 112: 113-132.

57. Geffen GM, Jones DL, Geffen LB. Interhemispheric control of manual motor activity. Behav Brain Res 1994; 64: 131-140.

58. Wyke M. The effects of brain lesions on the performance of bilateral arm movements. Neuropsychologia 1971; 9: 33-42.

59. Kimura D. Acquisition of motor skill after left-hemisphere damage. Brain 1977; 100: 527-542.

60. Vaughan HG, Costa LD. Performance of patients with lateralized cerebral lesions. II. Sensory and motor tests. J Nerv Ment Dis 1962; 134: 237-243.

61. Harrington DL, Haaland KY. Motor sequencing with left hemisphere damage: are some cognitive deficits specific to limb apraxia? Brain 1992; 115: 857-874.

62. Hammond GR. Hemispheric differences in temporal resolution. Brain Cogn 1982; 1: 95-118.

63. Haaland KY, Harrington DL. Limb-sequencing deficits after left but not right hemispheric damage. Brain Cogn 1994; 24: 104-122.

64. Haaland KY, Harrington DL, Yeo RA. The effects of task complexity on motor performance in left and right CVA patients. Neuropsychologia 1987; 25: 783-794.

65. Kimura D, Archibald Y. Motor functions of the left hemisphere Brain 1974; 97: 337-350.

66. Asanuma H. The Motor Cortex. New York: Raven Press, 1989.

67. Alexander GE, Crutcher MD. Preparation of movement: neural representations of intended direction in three motor areas of the monkey. J Neurophysiol 1990; 64: 133-150.

68. Alexander GE, Crutcher MD. Neural representation of the target (goal) of visually guided arm movements in three motor areas in monkey. J Neurophysiol 1990; 64: 164-178.

69. Georgopoulos A, Lurito JT, Petrides M, Schwartz AB, Massey JT. Mental rotation of the neuronal population vector. Science 1989 243: 234-236

70. Hoffman DS, Strick PL. Effects of a primary motor cortex lesion on step-tracking movements of the wrist. J Neurophysiol 1995; 73: 891-895. 
71. Pascual-Leone A, Grafman J, Hallett M. Modulation of cortical motor output maps during development of implicit and explicit knowledge. Science 1994; 263: 1287-1289.

72. Pascual-Leone A, Dang N, Cohen LG, et al. Modulation of muscle responses evoked by transcranial magnetic stimulation during acquisition of new fine motor-skills. J Neurophysiol 1995; 74: 1037-1045.
73. Karni A, Meyer G, Jezzard P, et al. Functional MRI evidence for adult motor cortex plasticity during motor skill learning. Nature 1995; 377: 155-158.

74. Corwell B, Gerloff C, Deiber M-P, et al. Different involvement of primary motor cortex with increasing complexity of motor tasks. Neurology 1996; 46: A398. 